\title{
Lypsykarjanavetoiden ammoniakkipäästö
}

Maarit Hellstedt ${ }^{1)}$, Sari Luostarinen ${ }^{2)}$, Juha Grönroos ${ }^{3)}$, Hannu Haapala ${ }^{4)}$

1) Luonnonvarakeskus Luke, Kampusranta9 C, 60320 Seinäjoki, maarit.hellstedt@luke.fi

2)Luonnonvarakeskus Luke, Vuorimiehentie 2,02150 Espoo, sari.luostarinen@luke.fi

3) Suomen ympäristökeskus SYKE, Mechelininkatu 34a,00260 Helsinki, juha.gronroos@syke.fi

4) Agrinnotech, Kalevankatu 12b A26, 60100 Seinäjoki, hannuhaapala1@gmail.com

Lypsykarjanavetan ammoniakkipäästöjen määrä riippuu tuotantoyksikön sisälämpötilasta, muodostuvan lannan tyypistä, typpipitoisuudesta ja pH:sta, lannan käsittelytavasta sekä käytettävien kuivikkeiden laadusta ja käyttömäärästä. Maatalouden kaasumaisten päästöjen arviointiin on kehitetty kansainvälisten ohjeiden pohjalta kansalliset laskennat typpiyhdisteille (SYKE) ja hiiliyhdisteille (Luke). Pääosin ulkomaiseen päästötietoon perustuvan päästölaskennan luotettavuuden parantamiseksi tarvitaan riittävä määrä kotimaista, erilaisista käytännön olosuhteista mitattua päästötietoa.

Ammoniakkipäästöjä selvitettiin mittauksin kuudessa eri lypsykarjanavetassa eri vuodenaikoina noin yhden viikon mittausjaksoissa. Tulosten hyödyntämistä testattiin kansallisessa ammoniakkipäästömallinnuksessa.

Pihattojen ammoniakkipäästöt vaihtelivat merkittävästi sekä samalla tilalla eri vuodenaikoina että tilojen välillä ollen pääosin alle $5 \mathrm{~g} / \mathrm{lehmä/vrk.} \mathrm{Parsinavetoissa} \mathrm{ammoniakkipäästö} \mathrm{oli} \mathrm{keskimäärin} \mathrm{alle} 3.5$ g/lehmä/vrk. Lietelantavarastojen ammoniakkipäästö vaihteli 0.04-1.49 g N/m²/vrk.

Ammoniakkina haihtuvan typen osuus oli 1-17\% lannan ammoniumtypestä. Pihattojen keskiarvo, 5.5\%, on huomattavasti pienempi kuin päästömallissa oletuspäästökertoimella lietelannalle laskettu 17.6\%. Parsinavetoille mitattu keskiarvo, 9.3\%, on puolestaan suurempi kuin mallin tuottama alle 6\%. Lietesäiliöistä puolen vuoden varastoinnin aikana ammoniakkina haihtuvan ammoniumtypen osuus oli keskimäärin noin $10 \%$. Se on sama kuin päästömallin tuottama nettopäästökerroin.

Mitatut ammoniakkipitoisuudet olivat alhaisempia kuin aiemmin samankaltaisissa olosuhteissa mitatut. Mittaustuloksiin ja niiden suhteuttamiseen lannan typpisisältöön sisältyy useita epävarmuustekijöitä, joiden merkitys on arvioitava ennen tulosten viemistä esimerkiksi päästömallinnukseen. Suomessa on tehty verrattain vähän ammoniakkipäästömittauksia tuotantorakennuksista sekä lantaloista. Aikaisemmin ei myöskään ole mittauksia tehty samoista kohteista kaikkina vuodenaikoina. Siten saadut tulokset antavat uutta tietoa päästöjen vaihtelusta vuodenaikojen mukaan.

Saatuja tuloksia voidaan rajoitetusti hyödyntää maatalouden kaasumaisten päästöjen laskennassa. Tulosten käyttökelpoisuudessa täytyy huomioida, että kyseessä on vasta muutama mittaus muutamissa kohteissa. Lisäksi on käytetty uudenlaista dynaamista mittausmenetelmää, jota voitaisiin edelleen kehittää. Päästöjen mittaaminen vaatii huolellista anturivalintaa, instrumentointia ja edustavaa näytteenottoa. Käytetyt jatkuvasti mittaavat anturit mahdollistavat päästön muodostukseen vaikuttavien navettojen erojen aiempaa tarkemman analyysin. Tutkimuksen ja viranomaisvalvonnan tarkkuus- ym. vaatimukset ovat erilaisia kuin mitä mahdolliset tilatasolla käytettävät säätöjärjestelmien ohjausohjelmistot edellyttävät. Jatkossa tuleekin kehittää pidemmälle optimoidut ratkaisut, joilla päästömittauksia voitaisiin tehdä optimaalisin laatu-kustannussuhtein eri käyttötarkoituksiin.

Asiasanat: lypsykarjatuotanto, ammoniakkipäästö, mittaaminen 


\section{Johdanto}

Maatalouden ammoniakkipäästöistä suurin osa on peräisin kotieläintuotannosta ja niistä noin $70 \%$ on lähtöisin nautakarjasta. Suurin osa kotieläintuotannossa syntyvistä kaasumaista päästöistä on peräisin eläinten erittämistä sonnasta ja virtsasta sekä niistä muodostuvasta lannasta, mutta myös suoraan eläimestä sekä rehuista. Karjasuojasta muodostuvien ammoniakkipäästöjen määrä riippuu tuotantoyksikön sisäolosuhteista, pääasiassa sisälämpötilasta, muodostuvan lannan tyypistä, ominaisuuksista (typpi, pH) ja käsittelytavasta sekä käytettävien kuivikkeiden laadusta ja käyttömärärästä. Kaasuja muodostuu myös rakennuksen ulkopuolella varastoidusta ja pellolle levitetystä lannasta.

Maataloudesta peräisin olevaa ammoniakkipäästöjen määrää arvioidaan mallintamalla (Grönroos ym. 2009, Grönroos ym. 2017). Mallilla saatavan päästötiedon luotettavuus on suoraan verrannollinen käytettävissä olevan lähtötiedon luotettavuuteen. Koska Suomessa maatilojen ammoniakkipäästöjä on mitattu vain vähän, nykyinen päästömalli perustuu pääosin ulkomaiseen päästötietoon, joita on hyödynnetty kansainvälisten päästölaskentaohjeiden laadinnassa. Suomen viileämmän ilmaston vaikutuksia päästöihin on pyritty korjaamaan soveltamalla mallissa korjauskertoimia. Jotta mallin luotettavuutta voitaisiin parantaa, tarvitaan riittävä määrä kotimaista, erilaisista käytännön olosuhteista kerättyä päästötietoa.

Eläinsuojissa ammoniakkipäästömittauksia suomalaisissa olosuhteissa on kattavimmin tehnyt Frederick Teye, joka väitöskirjaansa (2008) varten mittasi ammoniakkipäästöjä lypsykarjanavetoissa Suomessa ja Virossa. Mitattujen navetoiden eläinpaikoista pääosa oli kuitenkin kylmissä, eristämättömissä navetoissa, kun Suomessa suurin osa eläimistä on viileissä/lämpimissä, ainakin osittain eristetyissä pihatoissa. Koska ammoniakin haihtuminen on voimakkaasti riippuvainen vallitsevasta lämpötilasta sekä eläinten ruokinnasta, Teyen tuloksia voidaan käyttää tausta- ja vertailumateriaalina, mutta ei suoraan Suomen lypsykarjanavetoista peräisin olevien ammoniakkipäästöjen arvioinnissa. Lisäksi Teyen työssä ei tuloksia esitetty lantatyypeittäin, mikä on päästölaskennalle välttämätöntä, koska päästöt eri lantatyypeillä ovat erilaisia. Vuonna 2013 lypsylehmistä noin 60\% ja 30-40\% muista naudoista oli Suomessa lietelantajärjestelmässä, loppujen ollessa kuiva-, kuivike- tai kuivikepohjalantajärjestelmässä (Grönroos 2014).

\section{Materiaalit ja menetelmät}

Lypsykarjanavetoista syntyviä ammoniakkipäästöjä mitattiin kuudessa kohteessa, noin yhden viikon mittausjaksoissa neljä kertaa vuodenajoista johtuvan vaihtelun selvittämiseksi. Mittauskohteista neljä oli viileitä (verho-/kennolevyseinät) pihattoja, joissa lantaa käsiteltiin lietteenä, sekä loput kaksi olivat parsinavettoja, joissa lanta käsiteltiin kuivikelantana. Lietesäiliön ammoniakkipäästömittaukset tehtiin kahdella näistä tiloista.

Mittauskohteiden pohjapiirustuksista määritettiin mittauspaikat, 3 tai 4 pistettä, joihin mitta-anturit sijoitettiin kolmelle korkeudelle, 0.1 m, 1.0 m ja 2.5 m Teyen (2008) väitöskirjassa esitettyjen mittauskorkeuksien mukaisesti. Kussakin kohteessa mitattiin tuotantorakennuksen sisäilmasta ammoniakki- ja hiilidioksidipitoisuutta Dräger PAC 7000 -antureilla 2 minuutin mittausvälillä sekä lämpötilaa ja suhteellista kosteutta TinyTag -antureilla 30 minuutin välein. Lisäksi lattialla olevasta lannasta otettiin koontinäyte ravinnemäärityksiä varten.

Ammoniakkipäästö laskettiin mitatun hiilidioksidin perusteella seuraavasti (Teye ja Hautala 2007):

$j_{\mathrm{CO} 2}=\left(q v_{\mathrm{CO} 2} \times \rho_{\mathrm{NH} 3} \times\left(\mathrm{Cg}_{\mathrm{NH} 3}-\mathrm{Cout}_{\mathrm{NH} 3}\right) \times 10^{-6}\right) \times A^{-1}$

jossa

$q v_{x}$ on ilmanvaihto $\left(\mathrm{m}^{3} / \mathrm{h}\right)$

$C g_{x}$ on kaasun konsentraatio rakennuksen sisällä (ppm)

Cout $_{x}$ on kaasun konsentraatio sisään tulevassa ulkoilmassa (ppm)

$\rho_{\mathrm{NH3}}$ on ammoniakin tiheys $\left(\mathrm{g} / \mathrm{m}^{3}\right)$

$A$ on lantakäytävien pinta-ala $\left(\mathrm{m}^{2}\right)$ 
Lantavaraston ympäriltä haihtuvan ammoniakin määrää mitattiin sovelletulla Schjøerringin ym. (1991) mastomittausmenetelmällä, jossa neljä $10 \mathrm{~m}$ korkeaa teleskooppista mittausmastoa sijoitettiin mahdollisimman lähelle mitattavan kohteen reunaa. Mastoihin kiinnitettiin passiiviputket $0.46 \mathrm{~m}, 1.84 \mathrm{~m}, 4.60 \mathrm{~m}$ ja $8.00 \mathrm{~m}$ korkeudelle lantalan reunasta. JTI:n laboratorio Ruotsissa analysoi passiiviputket ja laski niiden perusteella ammoniakkipäästön suuruuden Schjøerringin ym. (1991) menetelmän mukaisesti.

\section{Tulokset}

Keskimääräiset ammoniakkipäästöt mittauskohteista eri mittauskertoina on esitetty kuvassa 1. Pihatoiden ammoniakkipäästöt vaihtelivat merkittävästi sekä tilojen välillä että samalla tilalla vuodenaikojen mukaan. Mittausten mukaan ammoniakkipäästö ei ollut suoraan riippuvainen navetan sisälämpötilasta. Pihatoiden ammoniakkipäästö oli pääosin alle 5 g/lehmä/vrk (Taulukko 1). Parsinavetoiden ammoniakkipäästöt vaihtelivat 0.67 ja 6.74 g/lehmä/vrk välillä, ja olivat talvella selkeästi pienimmät. Keskimäärin ammoniakkipäästö parsinavetoista oli alle $3.5 \mathrm{~g} / \mathrm{lehmä/vrk.}$

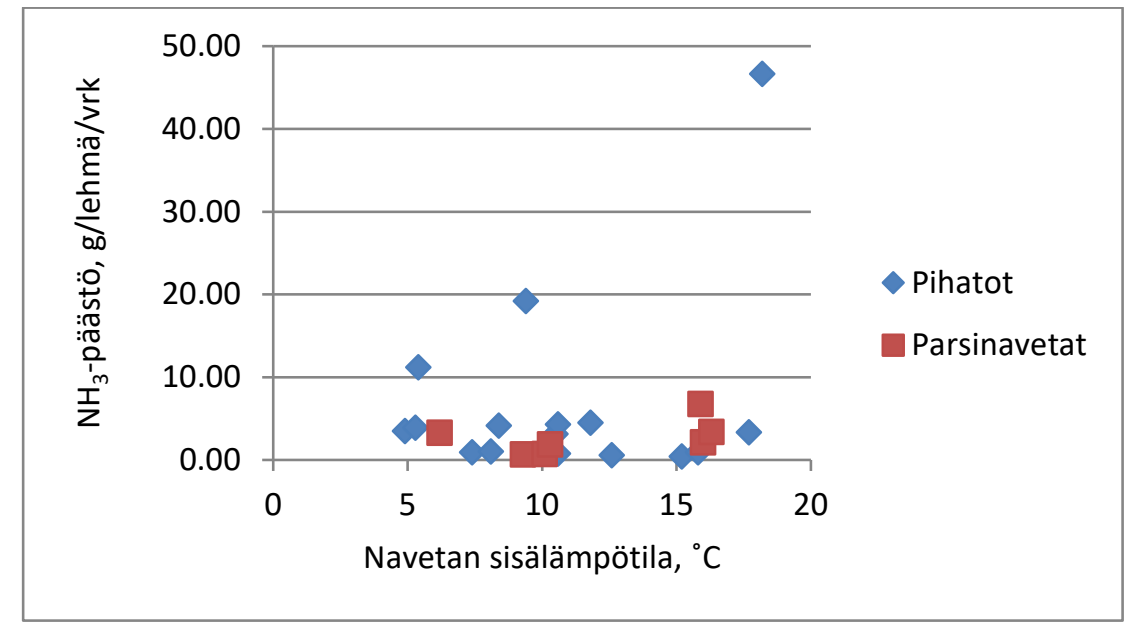

Kuva 1. Mittauskohteiden ammoniakkipäästön riippuvuus navetan sisälämpötilasta. Muista poikkeava mittaustulos (46.6 g/lehmä/vrk) aiheutui lannanpoistolaitteen toimintahäiriöstä eikä sitä huomioitu laskennassa (merkitty tähdellä Taulukossa 1).

Taulukko 1. Navetoista mitatut ammoniakkipäästöt tiloittain eri vuodenaikoina ja tilan keskimääräinen päästö, g/lehmä/vrk sekä lannan sisältämästä ammoniumtypestä navetassa haihtuva osuus, \%

\begin{tabular}{lllllll}
\hline & \multicolumn{3}{c}{ Pihatot } & \multicolumn{2}{c}{ Parsinavetat } \\
\hline Talvi & Tila 1 & Tila 2 & Tila 3 & Tila 4 & Tila 5 & Tila 6 \\
Kevät & 3.51 & 1.01 & 3.91 & 4.30 & 0.67 & 0.73 \\
Kesä & 3.12 & 0.79 & 4.15 & 0.93 & 2.14 & n/a \\
Syksy & 3.35 & $29.64^{*}$ & 0.55 & 0.40 & 3.41 & 6.74 \\
Keskiarvo & 11.21 & 19.21 & 0.94 & 4.48 & 1.87 & 3.29 \\
$\begin{array}{l}\text { \% lannan ammonium- } \\
\text { typestä }\end{array}$ & 5.23 & 11.42 & 2.37 & 2.55 & 2.04 & 3.55 \\
\hline $\begin{array}{l}\text { n/a = ei mittaustulosta antureiden toimintahäiriöiden takia } \\
\text { * lannanpoiston toimintahäiriöstä aiheutunutta päästöpiikkiä ei ole sisällytetty keskimääräiseen päästöarvoon }\end{array}$
\end{tabular}

Navetoista tehtyjen ammoniakkipäästömittausten, lattiapinnoilta kerättyjen lantanäytteiden ammoniumtyppipitoisuuden ja normilantalaskennan (Luostarinen ym. 2017a; liite c) antamien laskennallisten lantamäärien (lietelanta 23.46 tn/eläinpaikka/vuosi ja kuivikelanta 25.54 tn/eläinpaikka/vuosi) perusteella laskettiin lannan sisältämästä ammoniumtypestä navetassa ammoniakkina haihtuva osuus (Taulukko 1). Huomattavat 
erot tilojen välillä kuvaavat tilojen olosuhteita ja toimintatapoja. Pihatoista erottuu selvästi tila 3, jossa mittausjaksojen sisälämpötilat olivat tasaisesti koko joukon alimmat ja päästö siten pieni. Tilan 3 lanta oli analyysien mukaan selvästi muita väkevämpää, mikä myös painaa päästön osuutta alaspäin, koska se laskettiin suhteessa lannan typpipitoisuuteen. Lisäksi tilalla 3 oli lantaraappa myös kuilun pohjalla, joten lantaa poistettiin pihatosta tehokkaasti. Parsinavetoista tilalla 6 lantakourun pinta-ala lypsylehmää kohti oli alle puolet siitä, mitä tilalla 5 oli. Myös tuotantotekniikat olivat tiloilla erilaiset. Tilalla 5 lannan ammoniumtyppipitoisuus oli alhaisin. Tällöin pienestä ammoniakkipäästöstä/lehmä (Taulukko 1) huolimatta suhteellinen päästö voi muodostua suureksi, vaikka absoluuttinen päästö on pieni.

Lietesäiliöistä muodostuneet ammoniakkipäästöt (Taulukko 2) eivät mittausten mukaan ole suoraan riippuvaisia lämpötilasta, vaan siihen vaikuttavat myös muut tekijät, kuten tuuliolosuhteet, lietteen pinnalla oleva lumikerros ja kuorettuma sekä keväällä auringon vaikutuksesta muodostuvan sulan reuna-alueen suuruus. Lietesäiliöistä saatujen mittaustulosten ja lietesäiliöistä otettujen lantanäytteiden ravinnepitoisuuksien perusteella laskettiin lietesäiliöistä ammoniakkina haihtuneen typen määrä suhteessa säiliössä olleeseen lietelannan sisältämään ammoniumtyppeen (Taulukko 2).

Taulukko 2. Lietelantaloista muodostuneet ammoniakkitypen päästöt passiiviputkilla mitattuna eri vuodenaikoina sekä säiliöistä haihtuneen ammoniakkitypen määrä suhteessa säiliössä olleen lannan ammoniumtyppeen. Suluissa lämpötilan vaihtelu mittausjaksolla. Tilalla 5 tehtiin vain yksi mittaus.

\begin{tabular}{|c|c|c|c|c|c|c|c|c|}
\hline & \multicolumn{4}{|c|}{ Tila 1} & \multicolumn{4}{|c|}{ Tila 5} \\
\hline & $\mathrm{g} \mathrm{NH}_{3}-\mathrm{N} /$ & $\mathrm{g} \mathrm{NH}_{3}-$ & \% lannan & Ulkoläm- & $\mathrm{g} \mathrm{NH}_{3}-\mathrm{N} /$ & $\mathrm{g} \mathrm{NH}_{3}-$ & Ulkolämpö- & \% lannan \\
\hline & varasto-m² & $\mathrm{N} / \mathrm{vrk}$ & $\mathrm{NH}_{4}-\mathrm{N}:$ stä & pötila, ${ }^{\circ} \mathrm{C}$ & varasto-m² & $\mathrm{N} / \mathrm{vrk}$ & tila, ${ }^{\circ} \mathrm{C}$ & $\mathrm{NH}_{4}-\mathrm{N}$ :stä \\
\hline $\begin{array}{l}\text { Talvi, } \\
\text { maaliskuu }\end{array}$ & 0.99 & 620.3 & 0.06 & $\begin{array}{c}-0.5 \\
(-7.7-+5.6)\end{array}$ & & & & \\
\hline $\begin{array}{l}\text { Kevät, } \\
\text { toukokuu }\end{array}$ & 1.48 & 924.1 & 0.09 & $\begin{array}{c}8.1 \\
(2.0-17.9)\end{array}$ & & & & \\
\hline $\begin{array}{l}\text { Kesä, } \\
\text { heinäkuu }\end{array}$ & 0.97 & 609.7 & 0.07 & $\begin{array}{c}16.6 \\
(9.1-24.5)\end{array}$ & & & & \\
\hline $\begin{array}{l}\text { Syksy, } \\
\text { marraskuu }\end{array}$ & 0.15 & 92.7 & 0.01 & $\begin{array}{c}1.1 \\
(-5.4-+5.3)\end{array}$ & 0.04 & 12.5 & $\begin{array}{c}-2.1 \\
(-11.4-+0.6)\end{array}$ & 0.002 \\
\hline
\end{tabular}

\section{Tulosten tarkastelu}

Tässä tutkimuksessa havaitut sisäilman ammoniakkipitoisuudet asettuivat pääosin 1-5 ppm:n välille, kun Teyen (2008) tutkimuksessa viileiden pihatoiden sisäilman ammoniakkipitoisuus oli 3.4-17.4 ppm ja keskimäärin se oli 6.8 ppm. Wentaon ym. (2012) havaitsemat ammoniakkipitoisuudet kahdessa eri pihatossa olivat 1.46 ppm ja 5.73 ppm välillä, ollen molemmissa alimmat syksyllä. Ngwabien ym. (2009) eteläruotsalaisesta lietelantapihatosta mittaamat ammoniakkipitoisuudet olivat 1.70 ppm ja 17.93 ppm välillä. Sekä tämän tutkimuksen että Teyen (2008) tulosten mukaan ammoniakkipitoisuus ei ollut riippuvainen sisälämpötilasta. Sen sijaan Wentaon ym. (2012) mukaan ammoniakkipäästöpiikit seurasivat lämpötilan muutosta sisällä ja myös ulkolämpötilalla ja päästöllä oli merkittävä korrelaatio.

Määritetty keskimääräinen ammoniakkina haihtuvan typen osuus lannan ammoniumtypestä oli tässä tutkimuksessa pihatoissa 5.5\% ja parsinavetoissa 9.3\%. Ngwabien ym. (2009) tulosten mukaan ammoniakkina haihtuvan typen osuus oli 5.6\% lannan kokonaistypestä. Kaasikin ym. (2002) mukaan 4\% lannan kokonaistypestä häviää ammoniakkina käytettäessä sahanpurua kuivikkeena. Myös Gustafssonin ym. (2005) mukaan ko. päästön suuruus on 4\% lannan kokonaistypestä. Tämän tutkimuksen tulokset kokonaistyppeen suhteutettuna ovat samaa suuruusluokkaa.

Navetoista haihtuvan typen osuuden määrittelyssä lantanäytteet ovat merkityksellisiä. Vaikka lantanäytteiden näytteenottorutiini pyritään pitämään mahdollisimman vakiona, näytteissä on erityisesti kuivalannalla huomattavaa hajontaa, mikä aiheuttaa epävarmuutta laskettuihin haihtuneen ammoniakin suhteellisiin osuuksiin.

Lietesäiliöistä ammoniakkitypen päästö vaihteli tässä tutkimuksessa välillä $0.04-1.49 \mathrm{~g} \mathrm{NH}_{3}-\mathrm{N} \mathrm{m}^{-2}$ vuorokaudessa. Karlsson (1996) on mitannut vastaavalla tekniikalla tilamittakaavan kokeessa marras- huhtikuun mittausjaksolla keskimääräiseksi päästöksi $1.03 \mathrm{~g} \mathrm{NH}_{3}-\mathrm{N} \mathrm{m}^{-2}$ vuorokaudessa. Päästö on samaa suuruusluokkaa kuin tässä tutkimuksessa mitatut. Kyseisen ajanjakson typen hävikiksi on laskettu 2.2\% lannan kokonaistyppimäärästä. Pilottimittakaavan kokeen keskimääräiseksi päästöksi Karlsson (1996) sai 4.3 g $\mathrm{NH}_{3}-\mathrm{N} / \mathrm{m}^{2}$ vuorokaudessa, mitä hän pitää suurena. Syyksi oletetaan sitä, että mittaukset on tehty 
myöhäiskeväällä/kesällä, jolloin lietteen lämpötila on ollut $+19{ }^{\circ} \mathrm{C}$. Maasikmets ym. (2015) mukaan lietesäiliöstä muodostuva ammoniakkipäästö on keskimäärin $0.3 \mathrm{~g} \mathrm{NH}_{3} \mathrm{~m}^{-3}$. Mittaukset on tehty Virossa 650 lypsylehmänavetan lietesäiliöistä eri vuoden aikoina lämpötilan vaihdellessa $-2{ }^{\circ} \mathrm{C}$ ja $+23^{\circ} \mathrm{C}$ välillä. Käytännön olosuhteista saatuja päästöarvoja verrattiin myös päästölaskentamallissa sovellettaviin laskentaohjeistuksen mukaisiin päästökertoimiin.

Suomessa lypsykarjan lietelannasta 29\% ja 34\% kuivikelannasta muodostuu parsinavetoissa ja loput pihatoissa. Tämä ja hankkeessa mitatut eläinsuojan ammoniakkipäästöt huomioiden saatiin keskimääräiseksi haihtuvaksi osuudeksi noin seitsemän prosenttia eritetyn lannan ammoniumtypestä lietelanta- ja kuivikelantajärjestelmissä. Tämä on noin puolet pienempi kuin päästömallin tuottamat vastaavat arvot (14.2\% lietelannalle ja 13\% kuivikelannalle). Lantavarastoista puolen vuoden varastoinnin aikana ammoniakkina haihtuvan ammoniumtypen osuus oli tulosten mukaan keskimäärin noin $10 \%$. Se on sama kuin päästömallin käyttämä nettopäästökerroin.

Useat tukijat ovat todenneet, että alueelliset mittaukset ovat oleellisia luotettavien päästökerrointen ja sitä kautta laskettavien päästöjen kokonaismäärien selvittämiseksi. (GrootKoerkamp ym. 1998, Amon ym. 2001, Jungbluth ym. 2001, Snell ym. 2003, Zhang ym. 2005, Starmans ja Van der Hoek 2007). Tämän tutkimuksen tulokset vahvistavat tätä havaintoa.

\section{Johtopäätökset}

Kirjallisuudessa esitetyt ammoniakkipitoisuudet navetoissa vaihtelevat ja ovat sekä tässä tutkimuksessa saatuja tuloksia pienempiä että suurempia. Mittaustuloksiin ja niiden suhteuttamiseen lannan typpisisältöön sisältyy epävarmuustekijöitä, joiden merkitys on arvioitava ennen kuin tuloksia voidaan viedä esimerkiksi päästömallinnukseen. Suomessa on tähän mennessä tehty verrattain vähän ammoniakkipäästömittauksia tuotantorakennuksista sekä lantaloista. Yhtään tutkimusta ei ole aikaisemmin tehty siten, että mittauksia olisi tehty samoista kohteista kaikkina vuodenaikoina. Siten saadut tulokset antavat uutta tietoa päästöistä ja niiden vaihtelusta vuodenaikojen mukaan.

Hankkeen tuloksia ei voida suoraan hyödyntää maatalouden kaasumaisten päästöjen laskennassa, sillä kyseessä on vasta muutama mittaus muutamissa kohteissa. Lisäksi on käytetty uudenlaista dynaamista mittausmenetelmää, jota voitaisiin edelleen kehittää. Tällä hetkellä käytettyjen suurempaan mittausaineistoon perustuvien kansainvälisten kerrointen ja niiden kansallisten korjauskerrointen sivuuttamiseksi tarvittaisiin merkittävästi enemmän kotimaista mitattua dataa eri olosuhteista edustavamman päästötiedon perustelemiseksi. Päästöinventaarioiden kansainväliset menettelyt on voitava perustella täsmällisesti. Sitä vastoin tuloksia voidaan jo nyt harkitusti hyödyntää Luken ja SYKEn yhteisten päästölaskentajärjestelmien kehittämisessä sekä Luken ja SYKEn luomassa normilantalaskentajärjestelmässä (www.luke.fi/projektit/normilanta; Luostarinen ym. 2017a, b).

Nyt tehdyt mittaukset vahvistavat käsitystä siitä, että muiden maiden kertoimet eivät suoraan sovellu Suomessa käytettäviksi. Korjauskertoimia käytetäänkin tästä syystä päästömallissa jo nyt. Lantaloille ne toimivat nyt tehtyjen mittausten perusteella hyvin. Eläinsuojien päästöissä mittauksia tulisi kuitenkin tehdä lisää, jotta nykyistä mallia voisi perustellusti muuttaa. Tosin on tärkeää huomioida myös se, että mittauksiin ja varsinkin mittaustulosten suhteuttamiseen lannan ammoniumtyppimäärään sisältyy epävarmuuksia. Suomen olosuhteita kuvaavien, luotettavien päästökerrointen luomiseksi tarvitaan jatkossa lisää mittauksia erikokoisista, eri rakennusteknisten ratkaisujen mukaisista, erilaisilla tekniikoilla varustetuista navetoista sekä liete- että kuivalantaan perustuen. Tätä varten tulee käynnistää tähän nimenomaan keskittyviä hankkeita, jolloin varmistetaan saatavan datan käyttökelpoisuus mallinnustarkoituksiin. Kansainvälinen yhteistyö erityisesti Suomen naapurimaiden kanssa olisi suotavaa kustannustehokkaan lisätiedon hankkimiseksi. Tietoa on mahdollista tuottaa myös muissa kotieläintuotannon olosuhteisiin keskittyvissä hankkeissa, kun tämä tietotarve otetaan huomioon jo hanketta suunniteltaessa.

Päästöjen luotettava mittaaminen edellyttää tarkkaa suunnittelua ja instrumentointia. Hankkeessa käytetyt sähköiset anturit soveltuvat mittaukseen, mutta taustapäästön vaikutuksen eliminoimiseksi menetelmään on kuitenkin kehitettävä. Jatkohankkeiden varassa onkin kehittää pidemmälle optimoidut tilatasolle soveltuvat ratkaisut, joilla päästömittauksia voitaisiin tehdä optimaalisin laatu-kustannussuhtein eri käyttötarkoituksiin. 


\section{Kiitokset}

Tätä tutkimusta on osittain rahoittanut Maatilatalouden kehittämisrahasto. Tutkijat haluavat erityisesti kiittää tutkimukseen osallistuneita tiloja mittausten mahdollistamisesta ja tarvittavien taustatietojen luovuttamisesta tutkijoiden käyttöön.

\section{Kirjallisuusviitteet}

Amon, B., Amon, T., Boxberger, J. \& Alt, C. 2001. Emissions of $\mathrm{NH}_{3}, \mathrm{~N}_{2} \mathrm{O}$ and $\mathrm{CH}_{4}$ from dairy cows housed in a farmyard manure tying stall (housing, manure storage, manure spreading). Nutrient Cycling in Agroecosystems 60: 103-113.

Groot Koerkamp, P.W.G., Metz, J.H.M., Uenk, G.H., Phillips, V. R., Holden, M.R., Sneath, R.W., Short, J.L., White, R.P., Hartung, J., Seedorf, J., Schroder, M., Linkert, K.H., Pedersen, S., Taka, H., Johnsen, J.O. \& Wathes, C.M. 1998. Concentrations and emissions of ammonia in livestock buildings in Northern Europe. Journal of Agricultural Engineering Research 70: 79-95.

Grönroos, J. 2014. Maatalouden ammoniakkipäästöjen vähentämismahdollisuudet ja -kustannukset. Ympäristöministeriön raportteja 26/2014. Helsinki. 92 s.

Grönroos, J., Mattila, P, Regina, K., Nousiainen, J., Perälä, P., Saarinen, K. \& Mikkola-Pusa, J. 2009. Development of the ammonia emission inventory in Finland. Revised model for agriculture. The Finnish Environment 8/2009. 60 p.

Grönroos, J., Munther, J. \& Luostarinen, S. 2017. Calculation of atmospheric nitrogen and NMVOC emissions from Finnish agriculture - Description of the revised model. Reports of the Finnish Environment Institute 37/2017. Gustafsson, G., Jeppsson, K. H., Hultgren. J \& Sanno, J. O. 2005. Techniques to reduce the ammonia release from a cowshed with tied dairy cattle. Agricultural Engineering International: the CIGR E-journal, 7.

Jungbluth, T., Hartung, E. \& Brose, G. 2001. Greenhouse gas emissions from animal houses and manure stores. Nutrient Cycling in Agroecosystems 60: 133-145.

Kaasik, A., Leming, R. \& Remmel,T. 2002. Nutrient losses (N, P, K) in dairy- and pig production. Agraarteadus, 13: 201-211.

Luostarinen, S., Grönroos, J., Hellstedt, M., Nousiainen, J. \& Munther, J. 2017a. Suomen normilanta - laskentajärjestelmän kuvaus ja ensimmäiset tulokset, suomenkielinen tiivistelmä. Luonnonvara- ja biotalouden tutkimus 47/2017.

Luostarinen, S., Grönroos, J., Hellstedt, M., Nousiainen, J. \& Munther, J. 2017b. Finnish Normative Manure System - System documentation and first results. Natural resources and bioeconomy studies 48/2017.

Maasikmets, M., Teinemaa, E., Kaasik, A. \& Kimmel, V. 2015. Measurement and analysis of ammonia, hydrogen sulphide and odour emissions from the cattle farming in Estonia. Biosystems engineering 139: 48-59.

Ngwabie, N.M., Jeppsson, K.-H., Nimmermark, S., Swensson, C. \& Gustafsson, G. 2009. Multi-location measurements of greenhouse gases and emission rates of methane and ammonia from a naturally-ventilated barn for dairy cows. Biosystems engineering 103: 68-77.

Schjøerring, J. K., Sommer, S.G. \& Ferm, M. 1991. A simple passive sampler for measuring ammonia emission in the field. Water, Air, and Soil Pollution 62:13-24.

Snell, H. G. J., Seipelt, F. \& Van den Weghe, H. F. A. 2003. Ventilation rates and gaseous emissions from naturally ventilated dairy houses. Biosystems Engineering 86: 67-73.

Starmans, D. A. J. \& Van der Hoek, K. W. 2007. Ammonia, the Case of the Netherlands. Wageningen Academic Publishers. 201 p. ISBN 9789086860289

Teye, F. 2008. Microclimate and gas emissions in dairy buildings: Instrumentation, theory and measurements. Academic dissertation. Department of Agrotechnology University of Helsinki Finland. https://helda.helsinki.fi/handle/10138/20762.

Teye, F. \& Hautala, M. 2007. Measuring ventilation rates in dairy buildings. International Journal of Ventilation 6: 247-256.

Wentao, W., Guoqiang, Z. \& Peter, K. 2012. Ammonia and methane emissions from two naturally ventilated dairy cattle buildings and the influence of climatic factors on ammonia emissions. Atmospheric Environment 61: 232-243.

Zhang, G., Strom, J.S., Li, B., Rom, H. B., Morsing, S., Dahl, P. \& Wang, C. 2005. Emission of ammonia and other contaminant gases from naturally ventilated dairy cattle buildings. Biosystems Engineering, 92: 355-364. 